\title{
La interpretación patriarcalista de la monarquía absoluta de Fernando VII según «Los Persas»
}

\author{
JAVIER LÓPEZ Alós \\ Universidad de Murcia
}

\begin{abstract}
The patriarchalist interpretation of the absolute monarchy of Ferdinand $7^{\text {th }}$ according to «Los Persas»
\end{abstract}

\begin{abstract}
RESUMEN
Este trabajo pretende realizar un análisis crítico de los supuestos conceptuales del llamado Manifiesto de los Persas, obra fundamental para entender la reacción absolutista que siguió a la revolución liberal de Cádiz y sustento doctrinal del golpe del 4 de mayo de 1814. Veremos las peculiaridades del absolutismo de tipo católico respecto del hobbesiano y la importancia que tiene para la reacción la utilización ideológica del derecho histórico en la impugnación de la obra constitucional. Asimismo, y en la sospecha permanente ante el engaño de los políticos, el indefenso pueblo quedará a salvo refugiado en el padre y soberano católico. Esa concepción patriarcalista, esencial a la restauración fernandina, se verá completada por una visión providencial y redentora del monarca, lo que determinará buena parte del sentido de la política del sexenio.
\end{abstract}

PALABRAS CLAVE: pensamiento reaccionario; contrarrevolución; absolutismo; derecho histórico; patriarcalismo; providencialismo.

\section{ABSTRACT}

This article tries to make a critical analysis of the conceptual assumptions of the called "Manifiesto de los Persas", the work fundamental to understand the absolutist reaction that it followed the liberal revolution of Cadiz and doctrinal sustenance of the blow of the 4th of May 1814. We will see the peculiarities of absolutism of catholic type respect to the hobbesian and the importance that the ideological use of the historical right in the opposition of the constitutional work has for the reaction. Also, and in the permanent suspicion before the deceit of the politicians, the defenseless people will be out of danger refugee in the father and catholic sovereign. That patriarchalist conception, essential to the fernandine restoration, will be completed by a providencial and redentor vision of the monarch, which will determine good part of the sense of the policy of "Sexenio».

\section{KEYWORDS:} reactionary thought; counterrevolution; absolutism; historical right; patriarchalism; providencialism. 


\section{INTRODUCCIÓN}

Cuando el regreso de Fernando VII a España era ya un hecho (consumado el 24 de marzo de 1814), un grupo de sesenta y nueve diputados absolutistas firmaron una representación al rey por la que exponían su versión de los principales acontecimientos políticos acaecidos en la nación durante su ausencia, el detrimento de sus derechos reales y la injusticia y abusos de las Cortes de Cádiz, cuyo efecto debía suspenderse y responsabilidades exigirse. Su autor es todavía una incógnita, ${ }^{1}$ y el título por el que generalmente se le conoce es el Manifiesto de los Persas. ${ }^{2}$ Pero además de ese examen diagnóstico del cuerpo político (corrupto), prescribían el tratamiento de sus males a través de un programa cuya justificación histórica, como veremos, es claramente una construcción ad hoc. Lo interesante, en suma, de este texto, desde el punto de vista de la historia de los conceptos políticos, es el análisis de la teoría del absolutismo que en él se presenta, elaboración que proporcionó un soporte intelectual al menos suficiente al primer sexenio fernandino, así como la manera en que se relaciona con otras empresas doctrinales en el mismo o muy parecido sentido. Ello significaba necesariamente la laminación de la obra liberal revolucionaria, a la que se podía añadir mácula de concertación con Bonarparte (\#31). No en vano, la reivindicación de la figura del rey se hace simétrica a la devaluación de moderados y liberales y sus fuentes filosóficas modernas. Pero hay más, la defensa del absolutismo que los Persas hacen tácitamente vuelve a recalcar la diferencia con la tradición del origen popular del poder desarrollada por la Escuela de Salamanca en la delicada cuestión de la translatio imperii. Pero los enemigos son otros de momento y habrá que sortear este tipo de dificultades hasta que se conjure el peligro común al —no tan homogéneo- partido servil, sintetizado en el liberalismo.

\section{EL ABSOLUTISMO CATÓLICO CONTRA ROUSSEAU, CONTRA LOCKE, CONTRA HOBBES.}

Cuando aquí hablamos de absolutismo no lo hacemos del genuino y moderno que teorizaran principalmente Bodino y Hobbes y opuesto a los cuerpos intermedios; sino a su contrario, el «falso» absolutismo católico que establece una mo-

\footnotetext{
1 Joaquín Varela Suanzes apunta como probable redactor al primero de sus signatarios, Bernardo Mozo del Rosal. "La teoría constitucional en los primeros años del reinado de Fernando VII: El Manifiesto de los «Persas» y la «Representación» de Álvaro Flórez Estrada, en Estudios dieciochistas en homenaje al profesor José Miguel Caso González, Instituto Feijóo de Estudios sobre el Siglo XVIII, Oviedo 1995, Vol. II, p. 418.

2 Representación y Manifiesto que algunos diputados a las Cortes ordinarias firmaron en los mayores apuros de su opresión en Madrid para que la Majestad del Sr. D. Fernando el VII a la entrada en España de vuelta de su cautividad, se penetrase del estado de la Nación, del deseo de sus provincias, y del remedio que creían oportuno, Aranjuez, 12 de abril de 1814. Edición y estudio a cargo de M. ${ }^{a}$ Cristina Diz-Lois. Universidad de Navarra, Pamplona, 1967. Puede encontrarse una edición digital en la Biblioteca Virtual Cervantes: www.cervantesvirtual.com
} 
narquía limitada también por éstos, aunque se diga absoluta. Esta distinción, como veremos, es indispensable para comprender la peculiaridad del caso español $y$, sin ir más lejos, la decisiva alianza entre el altar y el trono, y la permanente reivindicación del papel de estos cuerpos intermedios, la Iglesia y la nobleza, en la configuración del cuerpo político de la monarquía, es decir, aquí, de la nación. Su absolutismo se patentiza en su rechazo a los nuevos conceptos republicanos y liberales. Así por ejemplo, la soberanía nacional es un «absurdo político», se escribe en el parágrafo décimo. Los firmantes del Manifiesto rechazan lo que entienden supone sustituir la representación de la Iglesia, nobleza y pueblo por la de éste en exclusiva (\#8). Y que el poder legislativo recaiga sobre las Cortes en detrimento del monarca, sólo titular del ejecutivo:

«Algunos proponían monarquía templada; otros monarquía degenerada y fantástica, otros gobierno mixto, otros un monstruo de muchas cabezas. Unos, sólo querían reformas, otros regenerar, otros aniquilar todas nuestras instituciones, otros conciliar nuestras leyes, usos y costumbres antiguas con las que se constituyesen de nuevo" (\#9).

O lo que es lo mismo, una apropiación de privilegios. Hay algo así como un incipiente esquema de lucha de clases en esta explicación:

" La Nobleza siempre aspira a distinciones: el Pueblo siempre intenta igualdades: éste vive receloso de que aquélla llegue a dominar; la Nobleza teme que aquél no la iguale: si, pues, la discordia consume los gobiernos, el que se funda, en tan desunidos principios siempre ha de estar amenazado su fin» (\#21).

Se trata, para el autor o autores, de justificar el mantenimiento de unos privilegios, a partir de dos supuestos fundamentales que sólo con fines analíticos vamos a separar, pero cuya imbricación es inevitable para una cabal comprensión de este período, el derecho histórico y la indefensión popular ante los males de la novación, pero que se hallan íntimamente ligados por cuanto del olvido del primero depende la segundo situación. Por eso el Manifiesto de los Persas no sólo es, aunque por supuesto sí lo sea, una crítica al liberalismo en general, o a la aplicación particular de algunos de sus principios en España. Su teoría de la monarquía absoluta se construye contra el arsenal doctrinal de filiación lockeana, es cierto, porque es el enemigo a batir en ese momento, pero no olvida al contramodelo histórico por antonomasia, la monarquía absoluta de tipo hobbesiano. Aunque extenso, merece la pena leer atentamente el siguiente párrafo en el que se procede a la comparación del absolutismo patriarcal propuesto por los Persas y el protestante, al que no se cita. Sirve también para remarcar sutilmente los límites de la soberanía de Fernando apenas unas semanas antes de su Decreto en Valencia de 4 de mayo:

«La monarquía absoluta (voz que por igual oye el Pueblo con harta equivocación) es una obra de la razón y de la inteligencia: está subordinada a la ley divina, a la justicia y a las reglas fundamentales del Estado: fue establecida por derecho de 
conquista o por la sumisión voluntaria de los primeros hombres que eligieron sus Reyes. Así que el Soberano absoluto no tiene facultad de usar sin razón de su autoridad (derecho que no quiso tener el mismo Dios): por esto ha sido necesario que el poder Soberano fuese absoluto, para prescribir a los súbditos todo lo que mira al interés común, y obligar a la obediencia a los que se niegan a ella. Pero los que declaman contra el Gobierno monárquico confunden el poder absoluto con el arbitrario; sin reflexionar que no hay Estado (sin exceptuar las mismas Repúblicas) donde en el constitutivo de la Soberanía no se halle un poder absoluto. La única diferencia que hay entre el poder de un Rey y el de una República es que aquél puede ser limitado y el de ésta no puede serlo: llamándose absoluto en razón de la fuerza con que pueda ejecutar la ley que constituye el interés de las sociedades civiles. En un gobierno absoluto las personas son libres, la propiedad de los bienes es tan legítima e inviolable que subsiste aun contra el mismo Soberano que aprueba el ser compelido ante los tribunales, y que su mismo Consejo decida sobre las pretensiones que tienen contra él sus vasallos. El Soberano no puede disponer de la vida no puede disponer de la vida de sus súbditos, sino conformarse con el orden de justicia establecido en su Estado. Hay entre el Príncipe y el Pueblo ciertas convenciones que se renuevan con juramento en la consagración de cada Rey: hay leyes, y cuanto se hace contra sus disposiciones es nulo en derecho. Póngase al lado de esta definición la antigua Constitución Española, y medítese la injusticia que se le hace» (\#134).

\section{EL DERECHO HISTÓRICO}

La utilización ideológica de las fuentes jurídicas medievales, parcial e interesada, con fines legitimatorios, fue algo común a absolutistas y liberales, pero resulta imprescindible atender a esas invocaciones al derecho histórico si lo que tratamos es de estudiar una cuestión que tiene también una importantísima dimensión jurídica. No en vano, el conflicto entre constitución histórica y constitución jurídica obliga a revisar los cimientos mismos de la legalidad y la legitimidad de todo el proyecto gaditano, como el propio proceso de convocatoria de Cortes, uno de los grandes caballos de batalla de la discusión del momento y uno de los escollos, desde el punto de vista legal, más difíciles de salvar para los liberales. Pero lo llamativo del caso es que, en rigor, apropiación del derecho histórico a manos de unos y de otros no se compadecía con sus respectivas expectativas políticas: ni se podía justificar, como pretendían los serviles, el absolutismo desde planteamientos jurídicos medievales, ni se podía tampoco sostener el liberalismo sobre semejante fundamento. De ahí que hablemos aquí de una re-construcción de la tradición jurídica hispana para este momento, muy sintomática en el Manifiesto de los Persas, pero que se halla prácticamente en todos los reaccionarios.

La impugnación del principio de soberanía nacional en nombre de la tradición es constante en todo el pensamiento antiliberal del siglo XIX, como acaba de demostrar en un reciente libro Antonio Rivera. ${ }^{3}$ Aún más todavía si, como veremos, la

${ }^{3}$ Reacción y revolución en la España liberal, Biblioteca Nueva, Madrid, 2006. 
fundamentación de esa tradición es sagrada. Y es precisamente por eso que el conflicto con el liberalismo se torna más agrio, pues se trata de una nueva forma de Estado que se configura contra una que ya existe y de la que la religión es pieza basal. Partiendo de cómo José Luis Villacañas representa gráficamente el antagonismo, el mismo proceso constituyente acaba deviniendo en la no menos visualizable oposición: nación soberana versus nación tradicional. ${ }^{4}$ De este modo:

$\begin{array}{lll}\text { Sociedad civil liberal } & \text { versus } & \text { comunidad católica } \\ \text { Res publica constituyente } & \text { versus } & \text { derecho histórico, } \\ \text { NACIÓN SOBERANA } & \text { versus } & \text { NACIÓN TRADICIONAL. }\end{array}$

Así, en el parágrafo 136 puede leerse: «ser justo restituir a V. M. la Corona de sus mayores, sobre las antiguas bases que la fijó la monarquía». A decir de los Persas la Constitución de 1812 se opone a las leyes tradicionales del reino. Hay un conflicto irresoluble entre constitución jurídica y constitución histórica, que no cabe tratar de armonizar (ésa será la gran empresa, por ejemplo, de Martínez Marina). Rodrigo Fernández de Carvajal explica el recurso al derecho histórico por la crisis institucional de 1808 , momento en vendrían a coincidir oportunidad y proyecto: «La invasión francesa va acompañada de una crisis total en las instituciones políticas. Ante el vacío... surge el constitucionalismo histórico ${ }^{5}$. Mas, con independencia de la génesis, lo que es notorio y formula también y en todo caso Fernández de Carvajal es que en Cádiz se produce un conflicto que el autor caracteriza como: Derecho histórico versus Principios constitutivos ${ }^{6}$.

En el propio Manifiesto se observa cómo las Cortes de Cádiz vendrían a erigirse en constituyentes «contra el clamor de las antiguas Cortes de España... ¿habrá mayor desgracia, que no haber encontrado las Cortes de Cádiz cosa útil en los códigos que tenía la Nación recomendados con la experiencia de tantos siglos?» (\#65) En consecuencia y por todo ello, demandan al rey, cuyos derechos reales también están en juego (\#37), que: «con arreglo a las leyes, fueros, usos y costumbres de España... se suspendan los efectos de la Constitución y los decretos dictados en Cádiz» (\#41). La fidelidad al monarca a la que el artículo 7 obligaba era imposible de cumplir, se decía. Faltaban meditación, consentimiento y voluntad, además de contravenir un pacto anterior e imprescindible (\#42), el histórico. Lo acordado en Cádiz, según se protesta en el parágrafo cuarenta y siete, es nulo a todas luces porque no se compadece con las leyes del Reino. Luego veremos que hay también otros motivos para reclamar esa impugnación.

${ }^{4}$ José Luis Villacañas, «La nación católica. El problema del poder constituyente en las Cortes de Cádiz» en GonzÁLEZ, Fco. (ed.): Relatos de nación. La construcción de las identidades nacionales en el mundo hispánico, Iberoamericana, Madrid, 2005, pp. 159-178.

5 Fernández de Carvajal, Rodrigo: El pensamiento español en el siglo xix, Nausicaa, Murcia, 2003, p. 81.

${ }^{6}$ Cf. 83 y ss. 
El Manifiesto de 1814, en lo tocante a esta cuestión, procede al examen y de algunos artículos del texto doceañista y trata de subrayar sus contradicciones tanto internas:

"Que la Nación española es libre e independiente, y no es ni puede ser patrimonio de ninguna familia, ni persona. Y el Artículo 14 expresa: que el Gobierno de la Nación española es una monarquía moderada hereditaria: artículos inconciliables sin otra explicación, en que sólo brilla el deseo de mantener el nombre para defraudar la sustancia» (\#40),

como con los intereses del pueblo representados en las leyes antiguas:

«Dice el Artículo 3: Que la soberanía reside esencialmente en la Nación, y por lo mismo pertenece a ésta exclusivamente el derecho de establecer sus leyes fundamentales. La primera parte queda demostrado ser alucinación y agravio a la felicidad del vasallo; aunque se pretextaba ésta para la novedad. La segunda no es acomodable en boca de los diputados, que carecían del voto de la Nación para ello, y no podía en algún caso tratarse de leyes fundamentales nuevas; habiendo las antiguas, y más sensatas, con las cuales se había celebrado un pacto entre la Nación y el Rey; y si bien el antiguo despotismo ministerial había cometido abusos, éste no fue defecto del sistema» (\#41),

así como aquellas incongruencias que conjugan uno y otro problema: «Con razón se ha permitido cátedras para explicar la Constitución, pues por su letra en algunos pasajes está misteriosa... un proceder en infinito, y nunca se llegará el fin del pleito» (\#66).

Ha de insistirse en que aunque el uso del derecho histórico sea común a todo tipo de opiniones políticas en este período, resulta llamativo que la defensa de la monarquía absoluta pretenda descansar en la reivindicación de las antiguas cortes medievales (\#\#108 y ss.) ${ }^{7}$, que poco tienen que ver con el sistema absolutista, genuinamente moderno y que es justo el que terminó con ellas. Si atendemos al párrafo siguiente, en el que se hace crítica de la etapa inmediatamente anterior a la invasión, creemos que podrá verse mejor esa oportuna re-construcción a la que hacíamos referencia más arriba:

«No son, pues, fáciles de numerar las calamidades que se siguieron en el Reino del no uso o menosprecio de las Cortes. Testigo ha sido V. M. del despotismo ministerial en la última época, y aun añadimos con dolor, que fue víctima del mismo, lo que no hubiera experimentado si las leyes, si las Cortes, si las loables costumbres y fueros de España hubieran mantenido su antigua energía» (\#113).

7 El parágrafo 109 explica: «Los Monarcas gozaban de todas las prerrogativas de la soberanía, y reunían el poder ejecutivo y la autoridad legislativa, pero las Cortes de Castilla con su intervención templaban y moderaban este poderío", justa situación, según este parecer, que hizo crisis con la dinastía austriaca y el despotismo ministerial. Nótese el uso de eufemismos como «despotismo ministerial»o «última etapa» para referirse a la dinastía borbónica, mientras a los Austria se les menta sin mayor reparo. 
Pero, en un primer momento y sobre todo, el derecho histórico cumple para los partidarios del absolutismo una labor negativa, de refutación legal a las Cortes de Cádiz. Esa función destructiva del derecho comparado, se halla auxiliada por el análisis procedimental del propio legislativo liberal. El descrédito, pues, no podía ser mayor; las arbitrariedades iban desde los defectos en la composición de las Cortes, que causarían la nulidad de cuanto se actuó (\#32). De la misma manera, se denuncia el incumplimiento de su propio articulado en perjuicio de los súbditos (\#64) y excesos de toda índole nunca vistos. La libertad propugnada por los liberales en realidad no lo es, y los defectos de las Cortes no sólo aluden a su composición, sino también a su funcionamiento, según la denuncia común de todos los absolutistas:

«faltos éstos de libertad [«los diputados sensatos»], no se atrevían a manifestar su dictamen; y las sesiones llamadas secretas, sobre escasearse todo lo posible, no han merecido este nombre. Gritar alguna vez el Pueblo a la puerta sobre que se acabase, y cubrir de improperios a los que iban saliendo del Congreso y no eran del número de los que por lisonjear sus caprichos con voces sonoras y nada significantes merecían aplauso en las públicas, era el resultado» (\#52).

De tal manera: «Que los Diputados serían inviolables por sus opiniones [art. $128]$...esto ha tenido más excepciones que palabras» (\#53). Pero según la interpretación reaccionaria, los trastornos se darán también en el mismísimo orden público y la tranquilidad social. Así como en El manifiesto de los Persas, podemos leer en La España vindicada de José Joaquín Colón de $1811^{8}$, otro importante representante de la reacción contrarrevolucionaria, hay una crítica furibunda a otro de los rasgos de una sociedad civil liberal, cual es el de las garantías judiciales, que se consideran exageradas y contrarias a la eficacia procesal y punitiva: « $i E s$ posible, diría, que lo que intrínsicamente malo necesite de tantas y tan previas censuras?» ${ }^{9}$. No olvidemos que Colón desempeñaba una magistratura. En definitiva, toda alteración de la constitución histórica, de la tradición y las costumbres, de los principios de una secular monarquía católica... han de trocar ley en anarquía, felicidad en desastre y sabiduría en pecado.

Por eso el recurso al derecho histórico es tan importante en los escritores contrarrevolucionarios, no sólo cuando, como en el caso del Manifiesto de 1814, el retorno de Fernando VII era ya un hecho, sino en pleno debate constituyente y durante todo el período de Cortes. Escribe Colón en 1811 que la constitución histórica de España se corresponde a la justicia de las leyes y de la religión y a la necesidad política. Y lo que las Cortes de Cádiz están vulnerando son sus mismos principios: «Los derechos de población y de conquista fueron dictados por la necesidad, por la religión, y por la política; y es temeridad pretender de un golpe echarlos a tierra y

${ }^{8}$ La España vindicada en sus clases y autoridades de las falsas opiniones que se la atribuyen. Segunda edición, aumentada con las censuras de las Juntas Provincial de Cádiz y la Suprema; y la contestación del autor a la primera. Imprenta de Repullés, Madrid, 1814.

9 p. 47. 
anularlos» ${ }^{10}$. Atacar los privilegios de la nobleza es cuestionar su propia razón de ser: «¿Quién puede dudar, que en quitando a la nobleza los signos que la distinguen, y la hacen apreciable, se acaba y se evapora cual humo? »11, y la de la propia monarquía, pues «no puede haber monarquía sin nobleza» y "Monarquía la ha de haber en España, como la ha habido desde su más remoto origen, porque así lo ha querido la Nación» ${ }^{12}$.

La justificación de la supresión de tales privilegios en función del principio de igualdad equivale a la falacia. El de la igualdad sería, según Colón, un falso problema en realidad, pues ésta ya existiría (y no sólo en su acepción cristiana, como defiende el primer Joaquín Lorenzo de Villanueva Catecismo del Estado según los Principios de la Religión ${ }^{13}$, sino también en cuanto a lo civil) ${ }^{14}$ Y no menos falsas las imputaciones de abuso que contra la nobleza se lanzan: «son caprichosas las quejas y extorsiones que se vociferan, por intereses parciales y sórdidas ambiciones, contra los dueños de las jurisdicciones seculares»" ${ }^{15}$. Colón se apoya en una visión benéfica sobre el Antiguo Régimen y sus estructuras de propiedad, y, sin observar dificultad ni contradicción para ello, en la invocación de las Partidas («según así lo manda el señor don Alfonso el sabio» ${ }^{16}$ ), orden jurídico medieval sobre el que se pretende seguir organizando la propiedad (vida económica) en el siglo XIX: «apoyados en el citado solemne fuero alfonsino, venerado por nuestra posterior legislación "17.

Esta verdad es tan inconmovible que logra aunar política y religión. No se puede de buena fe acriminar a las clases privilegiadas: «Si hubiese alguno que sin deliberación o con ella así pensase... dudo que si medita y reflexiona los grandes perjuicios que puede causar a la nación y a los interesados, se atreva a acercarse al vestíbulo del altar sin arrepentirse ${ }^{18}$. E iría además contra lo que se entiende que es un gobierno social ${ }^{19}$, aun cuando pudiesen darse abusos e infracciones por parte de la autoridad, pues ello no da licencia para modificar el ordenamiento jurídico: si se han cometido inconveniencias, repárense. Tal es el principio, un orden acorde con la ley natural, la síntesis entre derecho histórico y derecho natural es lo que sanciona la legitimidad, justicia y bondad, en una palabra, la catolicidad de la propuesta absolutista.

10 p. 5.

11 p. 145.

12 p. 6.

13 Véanse sobre todo los capítulos V y VI. Además de la edición de la Imprenta Real, Madrid, 1793, hay una disponible en versión digital en www.cervantesvirtual.com

14 Colón, op. cit., p. 10.

15 p. 11.

16 p. 148.

17 íd., p. 27.

18 íd., pp. $18 \mathrm{~s}$.

19 íd. p. 20. 


\section{LA INDEFENSIÓN DEL PUEBLO Y EL PATRIARCALISMO}

Para los partidarios del absolutismo, al derribar las Cortes de Cádiz la estructura jurídica preexistente, en la que consistía la constitución histórica de España, lo que hacían los defensores del texto del 19 de marzo de 1812 era arremeter contra la libertad que aquélla garantizaba y había consolidado durante siglos. Así, hablaban de «amenazas tiránicas» (\#58), y son precisamente los partidarios del absolutismo los que se erigen en defensores de la libertad y del pueblo (\#94).

Fruto de ese celo aparece uno de los argumentos principales del Manifiesto contra la democracia, cual es el de la manipulación de las masas a favor de intereses no siempre confesables. Un tópico reaccionario que se halla desarrollado ya en Preservativo contra la irreligión ${ }^{20}$ de Fray Rafael Vélez, escrita apenas dos años antes del Manifiesto de los Persas y en el Manifiesto de Miguel de Lardizábal de $1811^{21}$. Contra los más elementales principios del derecho natural, de gentes y hasta del derecho público, la filosofía trama contra las legítimas potestades; dice la filosofía, al modo que tentaba el diablo en el desierto:

«alucinaré al Pueblo con lo que más dista de nuestros deseos: la voz de igualdad (siempre imaginaria), la de libertad (siempre una quimera en sociedad donde no manda la razón), la exención de cargas sin las que no puede existir un Estado: la irreligiosidad (detestada aún entre las Naciones más incultas) serán resortes prevenidos, para que corráis desenfrenados: os libertaré de la impugnación, y todo, todo será para vosotros, sin que de vuestra parte pongáis más que la animosidad y ciega condescendencia a mis proyectos, infernal tentativa para almas no ensayadas en la fidelidad monárquica!» (\#96).

Al fin y a la postre, el principio básico del buen gobierno es el de la conservación y la estabilidad, y la concurrencia excesiva y diversa y hasta antagónica de pareceres atrofia su normal desarrollo (\#125) y con ello la tradicional división estamentaria de la sociedad:

«...la democracia se funda en la inestabilidad e inconstancia; y de su misma formación saca los peligros de su fin. De manos tan desiguales como se aplican al timón, sólo se multiplican impulsos para sepultar la nave en un naufragio. O en estos gobiernos ha de haber Nobles, o puro Pueblo: excluir la nobleza destruye el orden jerárquico, deja sin esplendor la sociedad, y se la priva de los ánimos generosos para su defensa; si el Gobierno depende de ambos, son metales de tan dis-

20 VÉLEZ, Fray Rafael: Preservativo contra la irreligión, o los planes de la filosofía contra la religión y el estado, realizados por la Francia para subyugar la Europa, seguidos por Napoleón en la conquista de España, y dados a luz por algunos de nuestros sabios en perjuicio de nuestra patria. Imprenta de Repullés, Madrid, 1825, pp. 9, 12... En la p. 92 dice textualmente: «La falaz política moderna, es decir, la desvergüenza y el descaro, unidos a la simulación y perfidia, de que tantas lecciones da la filosofía de nuestro siglo a sus partidarios...»

${ }_{21}$ Manifiesto que presenta a la Nación el Consejero de Estado Don Miguel de Lardizábal y Uribe, uno de los cinco que compusieron el Supremo Consejo de Regencia de España e Indias, sobre su conducta política en la noche del 24 de setiembre de 1810, impreso por Nicolás Carratalá Menor y Hermanos, Alicante, 1811, pp. 18 y 22 , v. gr. 
tinto temple, que con dificultad se une por sus diversas pretensiones e intereses» (\#20).

La paz es difícil en democracia, entonces (\#22). Tras conseguirla con la ayuda inestimable de la Divina Providencia ${ }^{22}$, la indefensión del pueblo ante los males del siglo ha de ser resuelta. Posteriormente nos ocuparemos de este elemento providencialista. Pero antes, el punto de partida es claro: «el hombre no es perfecto, y esto no se salva con mudar de Constitución cada día» (\#103). Y es aquí, donde el patriarcalismo y el orden natural resplandecen como elemento positivo del discurso. El rey, como un padre, debe cuidar de sus vasallos como hijos suyos: «la monarquía no para el Rey, sí para la utilidad del vasallo fue establecida» (\#128). Para los contrarrevolucionarios, la soberanía de la nación recae en el monarca, por la propia seguridad de ésta: si hay riesgo en que todo dependa de una persona, éste se multiplica con el gobierno de muchos, cada cual con sus propios intereses y opiniones (\#135) Constantemente aparece el motivo de una constitución tiránica que iba a conducir al pueblo a su ruina (v. gr. \#79). De ahí que no baste pedir que Fernando no jure la Constitución (\#60), sino que también debe dejarla sin valor (\#143).

\section{PADRE Y SOBERANO CATÓLICO}

Del mismo modo, pues la religión es un elemento esencial a esta teoría (y a lo que constituirá la alianza entre el altar y el trono definitivamente teorizada por el capuchino padre Vélez entre 1812 y 1818 en su Apología del Altar y del Trono³), es la defensa de la gran prole nacional la que sirve también para apoyar la pervivencia de los regulares y para postular la conciliación de la profesión monástica con la política y los asuntos de gobierno (\#11). También por la protección del pueblo (contra el escándalo de la blasfemia, contra la amenaza del jansenismo...), condenan la abolición de la Inquisición por el decreto del 22 de febrero de 1813. Y es que el Santo Oficio no es sólo un mecanismo de control religioso, político y social; cumple también una función vertebradora del sistema del Antiguo Régimen español. Por así decirlo, opera como garantía de su persistencia. Suspendidas sus funciones, se queda a merced de las novedades del tiempo, la irreligiosidad o el jansenismo. Mas la catolicidad de la nación española está fuera de toda duda y forma parte de ésa su constitución histórica, amenazada por la del Doce, y que los Persas reclaman restaurar con el trono fernandino.

Fray Rafael Vélez, dentro de la más estricta ortodoxia católica, concibió una obra que puede considerarse como paralela y hasta complementaria del Manifiesto

22 «Dios ha enviado la Persona de V. M. para salvar a España de su naufragio», \#102.

23 VÉLEZ, Fray Rafael: Apología del Altar y del Trono. Historia de las reformas hechas en España en tiempo de las llamadas Cortes; e impugnación de algunas doctrinas publicadas en la Constitución, diarios y otros escritos contra la Religión y el Estado, 2 vols., Imprenta de Repullés, Madrid, 1825. 
de los Persas. Con más tiempo de elaboración, seis años, y con la ventaja de la constatación de un Fernando VII restaurado en su trono, desarrolla el cuerpo doctrinal suscrito por los sesenta y nueve diputados. Y proporciona una legitimidad, la católica, más profunda y eficaz que la que los Persas habían podido construir impelidos por la urgencia del momento. De hecho, lo que Vélez consigue es conciliar el absolutismo fernandino con la catolicidad absoluta de la nación, eso sí, como eclesiástico que es, deslizando su preferencia por esta última. Pero se trata de la tentativa de legitimación más ambiciosa de este período, toda una fundamentación mística del trono ${ }^{24}$. Siguiendo el dogma establecido, y apoyándose también en Bossuet $^{25}$, Vélez afirma la sociabilidad natural del hombre, la primigenia monarquía de Adán, uncido de Dios, y el establecimiento posterior de las naciones por las mismas fuentes de Libro Sagrado. Se trata de un extremo, el de la precedencia de la monarquía sobre la nación, de gran importancia, en el que se enfrenta a las tesis roussonianas, como, en su patriarcalismo, a las del propio Suárez ${ }^{26}$. Así por ejemplo puede verse en este párrafo:

«El orden sociable se destruiría si los reyes no hubieran existido antes que las naciones. ¿Hubo jamás hijos sin padres, pueblos sin fundadores, naciones sin un superior común, imperio alguno sin tener quien gobernase? ¡Ah! Los primeros padres fueron los primeros reyes: los primeros reyes con sus numerosos descendientes formaron las primeras naciones: las naciones pues no pudieron existir antes que las fundasen repetidas generaciones; generaciones que saliendo de un tronco común, de un común padre, llevaban consigo el soberano que las gobernaba y a quien todas obedecían ${ }^{27}$.

Mas la monarquía absoluta es el estado más acorde a la voluntad de Dios, que es quien bendice el trono de los reyes y sanciona su legitimidad: a través de los testimonios de la Revelación, a través del derecho natural. Por eso es sagrado el orden de sus potestades y por eso, frente a las modernas teorías del pacto social o la división de poderes: «La conservación del estado debe impelernos siempre a unas máximas muy distintas. A proporción de cómo los gobiernos se asimilen al imperio de Dios sobre las criaturas, y al de los padres sobre sus familias, se con-

${ }^{24}$ Sobre reacción y fundamento místico del trono, vid. Rivera, op. cit., pp. 239-242.

${ }^{25}$ Cf. Apología, t. II, p. 14.

26 Javier Herrero, en Los orígenes del pensamiento reaccionario español, Alianza Ed., Madrid, 1994, realiza una observación sumamente interesante, cuyas causas no llega a explicar: según este autor, a la vez que se atiende a tradiciones extranjeras, constitutivo esencial del pensamiento reaccionario español, se produce una fractura con la tradición católica española del Siglo de Oro, de procedencia jesuita principalmente. Habría que ver en qué medida este abandono es completo o sólo parcial y aparente: pues, en primer lugar, una cosa es que no se les mencione y otra muy distinta que no se les use; en segundo lugar, en el conjunto de este pensamiento no dejan de tener su importancia obras directamente hostiles a la Compañía, como el Catecismo de Villanueva, y al menos recelosas, como las de autores preocupados sobre todo por los derechos reales, verbi gratia los persas, cuyo patriarcalismo explícito dejaba en una situación muy delicada a los jesuitas. A este respecto puede verse mi trabajo «Villanueva contra Hervás. Absolutismo político y absolutismo religioso en la crisis política del Antiguo Régimen", en Cinta Canterla (ed.), Nación y Constitución, de la llustración al Liberalismo, Junta de Andalucía y Sociedad Española de Estudios del Siglo XVIII, Sevilla, 2006.

${ }^{27}$ Apología, t. II, p. 82. 
solidará su poder, será más uno, más fuerte, más invencible»28. No fue el caso del período de Cortes, dirá igual que los Persas, cuando: «Nuestro gobierno monárquico se muda casi en el de una república»29.

De la magnitud del mal que se ha bordeado y la concordancia entre la monarquía absoluta y la preferencia divina, y el derecho histórico y el derecho natural, parece lógico extraer la necesidad de protección de tan sagrado orden. Una de las amenazas cuyo acecho preocupan al tradicionalismo es el de la libertad de imprenta, uno de los genuinos derechos civiles liberales por excelencia. Sirva de ejemplo este fragmento de Colón:

«Si en una casa o familia de mucha o poca gente se permitiese o mandase la inaudita libertad de que cada uno de sus habitantes pudiese de palabra, o lo que es peor, por escrito, insultarse recíprocamente; publicar los defectos más ocultos de unos y otros, sin perdonar al amo y a sus dependientes... \&c., \&c., \&c.; pregunto: ¿podrá haber paz en semejante casa?»30

No es sólo, naturalmente, la libertad de imprenta. Hablar de ésta es hablar también de la libertad de opinión: «¿La división de opiniones no cría odios, y otros fatales efectos? " ${ }^{31}$ Los autores de este tipo de papeles, dice Colón, han introducido la cizaña entre sus compatriotas y también entre España y sus aliados. Las acusaciones de traición, en plena Guerra, no son asunto baladí, aunque son frecuentes entre los bandos presentes en Cádiz $^{32}$. Vueltas a publicar en 1814, igual que la propia representación contenida en el Manifiesto de los Persas, en lo referente a la delación de las conductas de unos y de otros, no pocos párrafos de estas obras tienen -hablamos de patriarcalismo- cierto aire de reclamación al padre que vuelve a gobernar la casa después de una larga ausencia. Un aire, eso sí, cargado de muerte.

\section{LA RESTAURACIÓN FERNANDINA: PROVIDENCIALISMO Y REDENTORISMO}

El pensamiento reaccionario, con unos componentes tan decisivos en su configuración como la reafirmación dogmática del catolicismo romano y la mitificación del pasado histórico, especialmente la Edad Media, no tiene problemas para asumir una particular filosofía de la historia ${ }^{33}$ de claras raíces agustinianas: el providencialismo. Veamos cómo la ejerce Vélez. El vínculo entre lo religioso y lo civil es

28 t. II, p. 86.

29 t. II, p. 136.

30 Colón, p. 46.

31 p. 136.

32 cf. p. 94.

33 Tal vez sea más adecuado, como propone Antonio Rivera, hablar de «teología de la historia» en este caso, op. cit, pp. 172-190. 
constante para el arzobispo de Santiago. Cuando se rompe, las consecuencias son nefastas; cuando se repara, es posible la redención, como la propia historia puede certificar:

«La España volvió a ser libre y feliz, luego que sus reyes y sus pueblos aplacaron las iras de un Dios, reformando sus costumbres, y dándose al cultivo de la religión cristiana.

Pudiera extender mi raciocinio por todo el orbe cristiano. La Inglaterra, la Polonia, la Holanda, la Francia, la Alemania, do quiera que ha estado la fe de Jesucristo, ínterin su moral y preceptos han sido obedecidos por los reyes y sus súbditos, el estado se ha visto floreciente, sus enemigos han sido humillados, vencidos. La historia general testifica estos hechos ${ }^{34}$.

Pero no sólo es la historia la que se halla determinada por esta concepción trascendente de la acción humana. También la propia política está sujeta a las mismas seguridades: quien desafía los designios divinos obtiene castigo ${ }^{35}$ :

«Los tronos vacilan más o menos a proporción de cómo los errores y escándalos se disminuyen o se aumentan. Dios, que trajo de los cielos a la tierra su religión divina para hacer la felicidad de la especie humana, no puede menos de castigar a los que la persigan, y premiar a los que la acatan ${ }^{36}$.

Comprobamos que también puede hablarse de premios, naturalmente. $Y$ es que todo apocalipsis ofrece su elemento positivo, la redención, decía ya en 1808 Antonio Capmany: después de la Guerra, «más santa aún que la de las Cruzadas», «en fin seremos mejores cristianos» ${ }^{37}$. En una idea que tiene su más clara continuidad en el Filósofo Rancio ${ }^{38}$, la oportunidad de purificar aquellos componentes que han conducido al desastre, en el discurso de Capmany, equivale a una vuelta a las raíces de la españolidad y tradición católica ${ }^{39}$ :

"Con esta guerra, terrible, pero saludable, instrumento para nuestra eterna prosperidad, no nos inocularán más el impío filosofismo y la corrupción de costumbres de sus venenosos libros que tanto daño han hecho en la juventud... Con esta guerra volveremos a ser españoles rancios a pesar de la insensata currutaquería, esto es, volveremos a ser valientes, formales y graves ${ }^{40}$.

José Joaquín Colón, en su España vindicada procede a una la interpretación histórica también atravesada por la idea de pecado y su lógica de la caída y re-

${ }^{34}$ Apología, t. I, p. 11.

35 Vid. también t. I, p. 26.

36 ĺd., p. 11.

${ }^{37}$ Centinela contra franceses, Tamesis Books Limited, London, 1988, p. 93.

${ }^{38}$ Alvarado, Francisco: Obras escogidas del Filósofo Rancio. La ciencia tomista, Madrid, 1912.

39 Destaca F. Entienvre la importancia política de estas propuestas, una vez vencido el invasor: «Estos consejos están también destinados a los hombres que van a sentar una nueva autoridad gubernativa en España», Capmany, op. cit., p. 44.

40 ibid., p. 89. 
dención. Napoleón, debe entenderse como un castigo divino: «Dios lo permite, y se ríe de sus criaturas en justo castigo de nuestra desunión e inmoralidad: de tales causas nacen precisa y naturalmente semejantes efectos». ${ }^{41}$ Los males tienen sus raíces en los anteriores desórdenes, en los propósitos subversivos del sagrado orden natural de las cosas:

«A la ruina de los imperios y gobiernos que ha reducido a su dura dominación, ha procedido en todos ellos la negra intriga popular de la muchedumbre contra todas sus clases, deshonrando a sus príncipes y magnates, pintándolos con los aborrecibles colores de sultanes, déspotas, tiranos, y causantes de su pobreza, desnudez y abatimiento. La individual ambición, y el natural anhelo de igualarles en distinciones y fortunas, produjeron por necesidad en el pueblo inferior el más implacable odio contra todos los que no se contasen en su crecido número. Sus gritos y clamores, atizados por los ocultos y comprados agentes del común usurpador, siempre iban enmascarados con el velo de la justicia, y con la falsa esperanza de mejorar su suerte» ${ }^{42}$.

Como se ve, el Manifiesto de los Persas no puede considerarse un documento aislado, por tanto. Más bien, la cristalización de toda la doctrina antiliberal de los años de vacancia fernandina, oportunamente elaborada y sellada por la Apología del padre Vélez. Por ejemplo, el reproche a las Cortes unánime en los serviles, que pretextaban la guerra con Francia ante la posibilidad de emprender cualquier reforma. Mas es de suma trascendencia si se aborda desde la perspectiva teológica, pues en la concepción providencialista de la historia que sostiene Alvarado, España ha de lograr de nuevo el favor de Dios tras una dura y larga, pero justa penitencia, recordemos a Capmany, por el pecado de «la filosofía francesa». La fuerza de estas categorías religiosas en el campo político se observan en estas líneas con meridiana claridad:

«En primer lugar somos católicos cristianos, nuestra sagrada religión nos enseña que las grandes calamidades vienen por los grandes pecados y que en las grandes calamidades debe ser nuestro recurso el Dios de las batallas y de las victorias. Pregunto ahora: ¿dónde está ahora el decreto conforme al piadoso, sólido y político proyecto que se leyó en las Cortes cuando estaba en la Isla por el que se prohibían los públicos escándalos, se refrenaba el lujo y desenvoltura, se reformaban las costumbres del pueblo, se exhortaba a los Obispos para las solemnes y continuas rogativas, se cerraban los teatros y casas de licenciosas diversiones, se introducía en la tropa la disciplina de la religión, se tomaban todos los recursos para aplacar la ira de Dios irritada por nuestros pecados y se ponían todos los medios que dictaba la humana prudencia para conseguir la victoria?»43

El providencialismo funciona para la reacción como un argumento que excede lo meramente religioso y las llamadas al auxilio divino. Constituye una herramienta política, una ideología, al servicio de la monarquía absoluta. Los elementos que

\footnotetext{
41 Colón, op. cit., p. 2.

42 íbid.

43 Alvarado, t. II, pp. 27ss.
} 
el dominico Francisco Alvarado, más conocido como el Filósofo Rancio, presenta - pecado, caída, redención- reclaman para su feliz consecución el arrepentimiento y la expiación de la culpa, que es colectiva: «el cuerpo de un cristiano es un miembro del cuerpo del cuerpo místico de Jesucristo " ${ }^{44}$, nos recordará Rancio en sus últimas cartas. De ahí que la intransigencia se trate de una empresa común porque común ha sido ya la ruina y sólo común puede ser la salvación patria: «todos los que nos llamamos cristianos, debemos guerrear contra la filosofía. No echamos, no, a los filósofos de la Iglesia, porque eso le toca a quien tiene la autoridad; pero decimos y diremos que ellos se han salido de su gremio y que por este crimen deben ser arrojados, no solamente de ella, más también de la nación y aun de la vida, a no ser que traten seriamente de enmendar la que tan impía y perjudicialmente emplean» ${ }^{45}$. Una propuesta, para el dominico, perfectamente conciliable con la caridad cristiana, y que da índice de la irreductibilidad del adversario en ese preciso momento histórico: «esta caridad que con su ejemplo y doctrina nos ha enseñado nuestro Salvador Jesucristo es la que nos pone en la necesidad de obligar al impío, o a que deje de serlo, o a que deje de ser. ¿Puede concebirse verdadero amor que no venga acompañado del celo ${ }^{46}$ " Invocar el derecho de gentes será el siguiente paso. La lógica interna de este pensamiento es coherente: «Al derecho natural se sigue inmediatamente el de gentes, y según éste ya nos encontramos con tribunales encargados de vengar los desacatos cometidos contra la Divinidad dondequiera que encontramos gentes» ${ }^{47}$. Y, de entre estos tribunales, el del Santo Oficio mejor que ninguno simbolizaba y desempeñaba esa intransigencia reclamada contra la heterodoxia y la impiedad, una actitud puesta por Rancio en relación con el mismo derecho natural: «Tiene usted, pues, ya aquí anteriormente a toda ley un tribunal de Inquisición, si puedo explicarme así, erigido en el interior de cada hombre; tiene la intolerancia religiosa... las semillas de la intolerancia civil» ${ }^{48}$. Y es que, en última instancia, las revoluciones son castigos de Dios, pero son también oportunidades que Dios brinda para la enmienda y perfeccionamiento de los hombres y sus sociedades. En este punto es donde el patriarcalismo incorpora la clave redentorista y donde las purgas del sexenio absolutista pueden reclamarse sin el menor recato, acentuando lo político, como los Persas, o lo religioso, como en este caso Alvarado. Si bien dejando muy clara la imposible separación de una y otra esfera.

Si nuestro análisis es certero, no hay que extrañarse del epíteto con el que a Fernando VII se le conoció en tiempos, «el Redentor». Más allá de los artificios laudatorios y las hipérboles, había un fondo de coherencia en el sobrenombre: si era verdad que Dios le había enviado para salvar a España del naufragio, como dice el parágrafo 102 del Manifiesto de los Persas, esto es, como remedio a un mal pro-

\footnotetext{
44 t. II, p. 219.

45 t. II, p. 66.

46 t. II, p. 50.

47 t. II, p. 73. Vid. también p. 79.

48 t. II, p. 72.
} 
ducto de la corrupción, entonces no debe extrañar la utilización en sentido estricto de apelativos como «redentor» o «providencial». Ello suponía, siguiendo el apólogo de Vélez, sobrenatural, divina, una cuota de legitimidad mayor para sus partidarios, pues no sólo por la evidencia queda justificado: «Llegó el 4 de mayo: cesaron los sustos, se disiparon las sospechas, apareció el iris de la paz sobre nuestro horizonte. Desde este día reinaron en la España la justicia, la paz, la confianza y seguridad pública; lo diré de una vez; fuimos españoles nada más»49, también la intervención directa de Dios nos muestra un Fernando, protector, padre y providencial: «La España toda reunida alrededor de su soberano, es como una familia sola que vive bajo el gobierno de un padre. ¿Puede Dios manifestársenos más visible, más benigno, más misericordioso? ${ }^{50}$ ”

Matizábamos más arriba la homogeneidad del pensamiento reaccionario, que se manifiesta sobre todo en su vertiente ultraconservadora y deletérea ante la obra liberal. Hay sin embargo señaladas diferencias que atañen al horizonte de expectativas que para los contrarrevolucionarios presentaba la eventual restauración fernandina. Así por ejemplo, la visión que los absolutistas del Manifiesto tienen de la figura regia soporta elementos patriarcales y providenciales en una síntesis que no se encuentra en el pensamiento de Rancio. Tal combinación sí se dará en la Apología del Altar y del Trono de Vélez, pero no en el dominico. Y no es que no se encuentren elementos providencialistas, los hemos visto, sino, y esto es muy llamativo, que éstos se vinculan siempre al territorio, no a la persona: hablan siempre de España, no de su monarca. Cierta distancia razonable, si es que en rigor se hablaba en serio de la reclamación de las antiguas cortes, incompatible con la de la monarquía absoluta. La incongruencia fue señalada ya en el mismo siglo XIX por el conde de Toreno, Bayo, Alcalá Galiano y Modesto Lafuente, y debe leerse como un recurso de ideológico, en el sentido de ocultación ${ }^{51}$. También en la misma línea de una providencialismo ideológico, el modo con que concluye el Manifiesto y encabezan las sesenta y nueve firmas puede entenderse como un penúltimo recordatorio a los servicios prestados y éstos mismos como parte de los instrumenta Dei en su plan de salvación:

«La divina Providencia nos ha confiado la representación de España para salvar su religión, su Rey, su integridad y sus derechos a tiempo que opiniones errados y fines menos rectos se hallan apoderados de la fuerza armada, de los caudales públicos, de los primeros empleos, de la posibilidad de agraciar y oprimir».

49 Apología, t. II, p. 297.

50 t. II, pp. 342 y s.

51 vid. Antonio Rivera: «Los orígenes contrarrevolucionarios de la nación española» en COLOM GoNZÁLEZ, Fco. (ed.): Relatos de nación. La construcción de las identidades nacionales en el mundo hispánico, Iberoamericana, Madrid, 2005, pp. 1023 ss. 


\section{CONCLUSIÓN}

El Manifiesto de los Persas constituye una fuente de primer orden para comprender los procesos de legitimación que acompañaron la Restauración fernandina y sirvieron de base para su régimen absoluto. Por un lado, la defenestración de la obra gaditana, sobre la que no se paran mientes en desacreditar no sólo por los hechos sino también por las intenciones; por otro, una peculiar y abusiva interpretación del derecho histórico y del propio pasado histórico para (re-)construir una tradición a la que vincular una política que en realidad muy poco tenía que ver con las necesidades y expectativas de los referentes invocados. $Y$ sin embargo, se trata de una suerte de justificación doctrinal de la nueva monarquía absoluta de gran eficacia desde el punto de vista del grado de éxito obtenido en los objetivos que se marca. El Decreto de 4 de mayo de 1814 y el propio gobierno del sexenio pueden acreditarlo. El Manfiesto de los Persas tiene la virtud, técnicamente hablando, de sintetizar en muy pocas páginas los principios esenciales a la reacción antiliberal, esos principios que hemos podido ver presentes en algunas obras significativas del mismo período, y que muestran una lógica -perversa, si se quiere, pero coherente- tremendamente resistente a la modernidad y los principios republicanos, liberales o democráticos, como puede verse a lo largo de todo el siglo: así, el rechazo a la soberanía popular en nombre de la constitución histórica, sancionada por la tradición y hasta las leyes divinas, que es la que más conviene al pueblo y que tiene en el rey a su padre protector y vigilante. Si este estado de cosas es el idóneo y Dios lo ha querido, habrá que protegerlo; en caso contrario, aparecerá el castigo en forma de revolución, de la que habrá que arrepentirse para ser perdonados y expiar, depurar, las culpas, de la misma manera que se premiará a los justos. Y a purgas y recompensas solemos llamarlo también Sexenio Absolutista. 